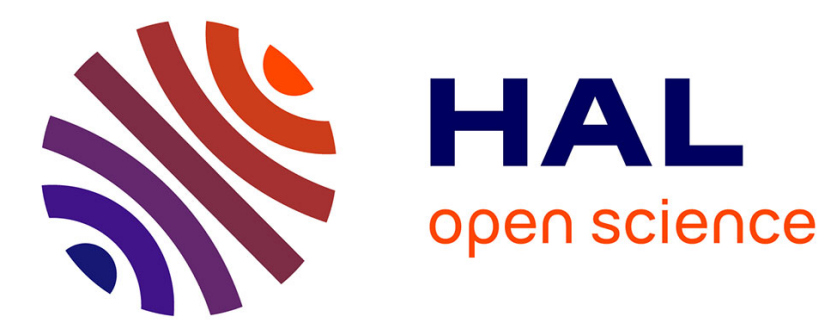

\title{
Impact of clinical factors and CYP2C9 variants for the risk of severe sulfonylurea-induced hypoglycemia
}

Andreas Holstein, Michael Hahn, Olaf Patzer, Angela Seeringer, Peter Kovacs, Julia Stingl

\section{- To cite this version:}

Andreas Holstein, Michael Hahn, Olaf Patzer, Angela Seeringer, Peter Kovacs, et al.. Impact of clinical factors and CYP2C9 variants for the risk of severe sulfonylurea-induced hypoglycemia. European Journal of Clinical Pharmacology, 2011, 67 (5), pp.471-476. 10.1007/s00228-010-0976-1 . hal-00657591

\section{HAL Id: hal-00657591 \\ https://hal.science/hal-00657591}

Submitted on 7 Jan 2012

HAL is a multi-disciplinary open access archive for the deposit and dissemination of scientific research documents, whether they are published or not. The documents may come from teaching and research institutions in France or abroad, or from public or private research centers.
L'archive ouverte pluridisciplinaire HAL, est destinée au dépôt et à la diffusion de documents scientifiques de niveau recherche, publiés ou non, émanant des établissements d'enseignement et de recherche français ou étrangers, des laboratoires publics ou privés. 
Impact of clinical factors and CYP2C9 variants for the risk of severe sulfonylurea-induced hypoglycaemia

\author{
A. Holstein', M. Hahn'1, O. Patzer'1, A. Seeringer ${ }^{2}$, P. Kovacs ${ }^{3}$, J. Stingl ${ }^{2}$ \\ 'First Department of Medicine, Clinic Lippe-Detmold, Detmold, Germany \\ ${ }^{2}$ Institute of Pharmacology of Natural Products \& Clinical Pharmacology, \\ University of Ulm, Germany \\ ${ }^{3}$ Interdisciplinary Center of Clinical Research, University of Leipzig, Germany
}

Address for correspondence:

Andreas Holstein MD

$1^{\text {st }}$ Department of Medicine

Klinikum Lippe-Detmold

Röntgenstr. 18

D - 32756 Detmold / Germany

Tel.: +49-5231-721171 Fax: +49-5231-721035

e-Mail: Andreas.Holstein@t-online.de 
Aims: The established risk factors for severe sulfonylurea-induced hypoglycaemia (SH) include low HbA1c, advanced age, long duration of diabetes, multimorbidity and polypharmacy. As the genetically polymorphic cytochrome P450 (CYP) enzyme CYP2C9 is mainly responsible for the hepatic metabolism of sulfonylureas (SUs), we hypothesized that the slow-metabolizer genotypes ${ }^{*} 2 /{ }^{*} 2,{ }^{*} 2 /{ }^{*} 3$ and ${ }^{*} 3 /{ }^{*} 3$ might be overrepresented in type 2 diabetic patients with $\mathrm{SH}$.

Methods: In a prospective population-based case-control study, CYP2C9 allelic variants of 102 diabetic patients with $\mathrm{SH}$ were compared to a matched group of 101 SU treated patients but without a history of SH. The 203 Caucasian patients had been treated with the SUs glimepiride, glibenclamide or gliquidone. SH was defined as a symptomatic event requiring treatment with intravenous glucose and was confirmed by a blood glucose measurement of $<50 \mathrm{mg} / \mathrm{dl} \quad(<2.8 \mathrm{mmol} / \mathrm{l}) .337$ Caucasian diabetic patients receiving oral antidiabetic drugs and 1988 healthy Caucasian volunteers who had been genotyped earlier served as further two control groups.

Results: In the univariate analysis only a low HbA1c value $(p=0.0004)$ was shown as a risk factor for $\mathrm{SH}$. There was no overrepresentation of the CYP2C9 ${ }^{*} 2 /{ }^{*} 2,{ }^{*} 2 /{ }^{*} 3$ and ${ }^{*} 3 /{ }^{*} 3$ variants in the $\mathrm{SH}$ group (2\%) compared to the control group (5\%). However, in the control group, patients with CYP2C9 genotypes predicting slower metabolism of SU drugs were treated with significantly lower doses $(p=0.027)$ than extensive metabolizers whereas in the patient group with severe hypoglycaemia, the dose was the same for all genotype groups.

Conclusions: In the present cohort of 102 patients with $\mathrm{SH}$, a low HbA1c value was related to the risk for $\mathrm{SH}$. There was no overrepresentation of the CYP2C9 slow metabolizer genotypes in the hypoglycaemic patients group observed but the drug 
exposure in the slow metabolizer genotypes was estimated to be higher in the hypoglycaemic patients which might partly have contributed to their risk for $\mathrm{SH}$.

Key words: type 2 diabetes mellitus - hypoglycaemia - sulfonylureas - CYP2C9 variants 


\section{Introduction}

Recent results from large interventional studies (1-3) for the prevention of vascular complications and data from observational studies (4) revealed that tight glycaemic control in patients with type 2 diabetes mellitus (T2DM) is of limited value. In particular, severe hypoglycaemia may even increase cardiovascular and all-cause mortality. These inferences apply also for sulfonylurea (SU) treated diabetic patients. Severe sulfonylurea-induced hypoglycaemia $(\mathrm{SH})$ is a life-threatening and pathophysiologically complex, multifactorial event. The established risk factors for $\mathrm{SH}$ include low $\mathrm{HbA1c}$, advanced age, long diabetes duration, extensive comorbidity with higher degrees of renal insufficiency, polypharmacy and the use of long-acting versus short-acting preparations $(5,6)$.

Characterizing the individual sensitivity to SUs, pharmacogenetic factors could be of additional critical importance for the risk of $\mathrm{SH}$. SUs such as glibenclamide, glimepiride, gliclazide or gliquidone are metabolized hepatically by the genetically polymorphic cytochrome P450 (CYP) enzyme CYP2C9 $(7,8)$. There have been few studies examining the role of CYP2C9 genotypes for the interindividual variability in drug response $(9,10)$ and mild hypoglycaemia (11). However, previous studies did not capture the significance of CYP2C9 variants in patients with experienced $\mathrm{SH}$. Only in a pilot study with a small sample size we could identify the CYP2C9 genotypes ${ }^{*} 2 /{ }^{*} 3$ and ${ }^{*} 3 /{ }^{*} 3$ that are predictive for low enzyme activity as further risk factors for SH in Caucasian individuals (12). In the present study we compared the distribution of different CYP2C9 allelic variants in a by international standards large cohort of patients with T2DM who experienced SH versus a matched control group without $\mathrm{SH}$. Furthermore, the frequency of CYP2C9 genotypes in the cases with $\mathrm{SH}$ was compared to a second, previously reported control sample of DNA from 337 Caucasian diabetic patients receiving oral antidiabetic drugs and without a history of 
severe hypoglycaemia, and to a further sample of 1988 healthy Caucasian volunteers.

\section{Patients and methods}

In this prospective population-based case-control study, 102 consecutive patients with T2DM and SH were genotyped concerning their CYP2C9 allelic variants and compared to a matched control group of $101 \mathrm{SU}$ treated patients but without a history of $\mathrm{SH}$. The hypoglycaemic patients as well as the control group were recruited at the medical department of the Clinic Lippe-Detmold, a large tertiary care hospital in East Westphalia, Germany, between 1 January 2000 and 31.12.2009. As the only hospital in the area, the one at Lippe-Detmold is responsible for the inpatient and outpatient management of all emergencies in a region with 200,000 inhabitants. Our study provided a sensitive detection of hypoglycaemia. As published previously, blood glucose testing was systematically performed in every emergency patient irrespective of the presenting condition, either already prehospitally at the scene of the emergency or immediately after the arrival at the emergency department, respectively. The entire emergency team underwent a structured training program concerning the diagnosis and therapy of diabetic emergencies $(6,13)$.

All investigated 203 Caucasian diabetic patients had been treated with the SUs glimepiride, glibenclamide (glyburide), or gliquidone and were monitored on an inpatient basis. Severe hypoglycaemia was restrictively defined as a symptomatic event requiring treatment with intravenous (i.v.) glucose and was confirmed by a blood glucose measurement of $<50 \mathrm{mg} / \mathrm{dl}(<2.8 \mathrm{mmol} / \mathrm{l})$. Creatinine clearance was calculated by the formula of Cockroft and Gault (14). Renal impairment was defined as a creatinine clearance of $<60 \mathrm{ml} / \mathrm{min}$. 
After informed consent $10 \mathrm{ml}$ EDTA blood samples from all 203 subjects were collected and CYP2C9 genotyping was performed with the methods described earlier (8). Clinicians and patients were blind to genotype. Frequency of genotypes in the cases with $\mathrm{SH}$ was compared to the matched control group. Furthermore, we performed a comparism between our cases with $\mathrm{SH}$ and a second control sample of DNA from 337 Caucasian diabetic patients receiving oral antidiabetic drugs and without a history of severe hypoglycaemia, and to a futher large sample of 1988 healthy Caucasian volunteers who had given their informed consent for genotyping (12). The protocol was approved by the Ethics Committee of the University of Münster School of Medicine and (for further comparison groups) by the Ethics Committee of the Charité University hospital, University medicine Berlin.

\section{Statistics}

Standard descriptive and comparative statistics (chi ${ }^{2}$ test, ANOVA) were used to characterize and compare clinical parameters in different groups (cases, controls). Logistic regression analyses were used to calculate the effects of investigated factors on severe hypoglycaemia events, which were reported as odds ratio with $95 \% \mathrm{Cl}$ (confidence intervals). Data were analyzed using the SPSS software package (version 18.0.2; SPSS, Inc., Chicago, IL).

\section{Results}

From $2000-2009$ a total of 1,419 cases of severe hypoglycaemia were registered among the 103,256 patients who attended the emergency department of the LippeDetmold Clinic. 39\% $(552 / 1,419)$ of hypoglycaemic events occurred in patients with type 1 - and $57 \%(809 / 1,419)$ in those with type 2 diabetes. In $4 \%(58 / 1,419)$ subjects 
with secondary diabetes and non-diabetics were affected. $10 \%(141 / 1,419)$ of all cases with severe hypoglycaemia have been treated with SUs. In two cases ingestion of SUs was accidental as two women with dementia took the SU preparations from their husbands. Genotyping could be performed in 102 subjects with $\mathrm{SH}$ as another 37 patients were not able to consent due to their demented state or explicitely gave no consent.

All 102 patients with SH demonstrated neuroglycopenic disturbances, their plasma glucose levels were $31.8 \pm 10.4 \mathrm{mg} / \mathrm{dl}(1.76 \mathrm{mmol} / \mathrm{l})$ prior to treatment with i.v. glucose. The distribution and mean daily dose of SU agents were comparable between hypoglycaemic subjects and controls. Table 1 demonstrates the basic characteristics of all hypoglycaemic subjects versus the control group indicating a comparable geriatric and multimorbid state in both groups. The control group without $\mathrm{SH}$ had even a higher degree of renal impairment and received more additional comedication which were main substrates of CYP2C9 than those with $\mathrm{SH}$, in particular torasemide, clopidogrel, phenprocoumon, diclofenac or fluvastatine.

Logistic regression analysis revealed a low $\mathrm{HbA1c}$, presence of coronary heart disease $(\mathrm{CHD})$, the CYP2C9-genotypes $\left({ }^{*} 1 /{ }^{*} 2\right.$ and $\left.{ }^{*} 2 /{ }^{*} 3\right)$ and comedication with other CYP2C9 main substrates as significant risk factors for $\mathrm{SH}$ (Table 2). The effects of these predictors appeared to be independent of each other as they remained statistically significant in logistic regression analysis even upon including all risk factors in the model $(\mathrm{HbA} 1 \mathrm{c}$, presence of $\mathrm{CHD}$ and comedication with other CYP2C9 main substrates; all $\mathrm{p}<05)$. The kind of accommodation of the patients, their previous diabetes education, different comorbidities (dementia, heart failure) or comedication (insulin, metformin, ACE-inhibitors etc.) did not influence the risk of SH. There was no overrepresentation of the CYP2C9 slow metabolizer genotypes ${ }^{*} 2 /{ }^{*} 3$ and ${ }^{*} 3 /{ }^{*} 3$ in our group with $\mathrm{SH}$ compared to the control group. Accordingly, we found 
no significant differences in the distribution of CYP2C9 allelic variants compared with two other previously reported control samples (12) consisting of 337 Caucasian diabetic patients receiving oral antidiabetic drugs and without a history of $\mathrm{SH}$, and to a large cohort of 1988 healthy Caucasian volunteers (Table 3).

By expressing drug dosing as a dose factor with $3.5 \mathrm{mg}$ glyburide, $1 \mathrm{mg}$ glimepiride, and $30 \mathrm{mg}$ gliquidon as normal dose with dose factor 1 , we calculated mean doses in the CYP2C9 metabolizer groups extensive (alleles CYP2C9* $1 /{ }^{*} 1,{ }^{*} 1 /{ }^{*} 2$ ), intermediate $\left(\right.$ CYP2C $\left.{ }^{*} 1 /{ }^{*} 3\right)$ and slow $\left(\right.$ CYP2C9*2/*2, ${ }^{*} 2 /{ }^{*} 3$ and $\left.{ }^{*} 3 /{ }^{*} 3\right)$. The mean SU dose was 2.3, 1.8 and 1.7 in the extensive, intermediate and slow metabolizer groups in the control group and 2.5, 2.9 and 2.8 in the hypoglycaemic patients group. A significant lowering of the doses thus could be observed in the control group $(p=0.027)$ while in the hypoglycaemic patient group, no such empirical dose adjustment to genotype was seen. 


\section{Discussion}

The current ten-year population based study suggest that apart from the established clinical risk conditions, CYP2C9 allelic variants do not strongly contribute to the individual susceptibility for severe hypoglycaemia associated with the use of glimepiride and glibenclamide. The frequency of the CYP2C9 slow metabolizer genotypes ${ }^{*} 2 /{ }^{*} 2,{ }^{*} 2 /{ }^{*} 3$ and ${ }^{*} 3 /{ }^{*} 3$ in our cohort of 102 Caucasian individuals with $\mathrm{SH}$ did not differ from that observed in the control group.

SUs are mainly metabolized by the genetically polymorphic cytochrome enzyme CYP2C9. The rare CYP2C 9 genotypes ${ }^{*} 2 /{ }^{*} 2,{ }^{*} 2 /{ }^{*} 3$ and ${ }^{*} 3 /{ }^{*} 3$ are predictive for low enzyme activity. In vitro and in vivo studies showed a modest reduction of the enzyme activity in healthy volunteers with the CYP2C9*2 polymorphism and a strong reduction in those with the CYP2C9*3 polymorphism. Compared with the CYP2C9* ${ }^{*} /{ }^{*} 1$ genotype, the tolbutamide clearance in subjects with the CYP2C9*2/*2 genotype was reduced by $25 \%$ and in those with the CYP2C9*3/*3 genotype by $84 \%$ (7). Pharmacokinetic studies in healthy subjects revealed that clearance of glibenclamide and glimepiride in CYP2C $9^{*} 3 /{ }^{*} 3$ carriers was only $20 \%$ of that in the wild type carriers (8). Also non-diabetic carriers of the CYP2C9*2/*3 genotype had a significantly reduced clearance of glibenclamide and glimepiride (9). Using these SUs, the drug exposure was increased 1.3 - to 2.8 -fold in volunteers with a CYP2C9*3 allele compared to those with the CYP2C9*1/* 1 genotype $(9,15,16)$. In CYP2C9*3 allele carriers using tolbutamide, the prescribed dose was lower compared to patients with the wild-type CYP2C9 genotype. No differences in the prescribed dose were found in tolbutamide users with the CYP2C9*1/*2 or CYP2C9*2/*2 genotype compared to wild-type patients or in patients using glibenclamide, gliclazide, and glimepiride (10). Recent data from the Go-DARTS Study in $1,073 \mathrm{SU}$ treated patients (80\% received gliclazide) indicated that patients 
with two copies of the CYP2C9*2 or CYP2C9*3 loss-of-function alleles were 3.4 times more likely to achieve a treatment $\mathrm{HbA} 1 \mathrm{c}$ level of $<7 \%$ as compared with wild type carriers resulting in a $0.5 \%$ greater reduction in $\mathrm{HbA} 1 \mathrm{c}$ (17). Indeed, we observed an empirically lower dosing in patients with the genotypes ${ }^{*} 2 /{ }^{*} 2,{ }^{*} 2 /{ }^{*} 3$ and ${ }^{*} 3 /{ }^{*} 3$ within the control group indicating that clinicians and patients got sensibilized to the lower oral clearance of the SU drugs due to the CYP2C9 genotypes and took lower doses. Interestingly, we did not observe these genotype based dosing within the hypoglycaemic patients group. A higher drug exposure, thus, might have contributed to the risk of hypoglycaemia in patients with the CYP2C9 slow metabolizer genotypes.

Our study examined CYP2C9 allelic variants in a typical cohort with experienced SH. As there is no consensus, definition of hypoglycaemia in diabetes is a critical point. Our definition of severe hypoglycaemia as an event with neuroglycopenic symptoms requiring treatment with i.v. glucose and confirmation by a blood glucose measurement of $<50 \mathrm{mg} / \mathrm{dl}(<2.8 \mathrm{mmol} / \mathrm{l})$ was chosen restrictively and indisputable in large degree with the definition of the ADA (18) and comparable studies (19). Whereas in a recent study by Ragia et al. (11) the diagnosis of hypoglycaemia was assessed retrospectively and was not based on accepted standards as it included self-reported unspecific symptoms with incomplete confirmation of a blood glucose concentration of $<65 \mathrm{mg} / \mathrm{dl}(<3.6 \mathrm{mmol} / \mathrm{l})$. The authors demonstrated that the CYP2C9*3 allele was a determinant for mild hypoglycaemia in 92 patients treated with glimepiride or glicazide. However, compared with our cohort their patients were significantly younger (mean age 68 vs. 77 years), less morbid and with a poor metabolic control ( $\mathrm{HbA1c} 7.6$ vs. $6.5 \%$ ), thus predicting an a priori low risk for hypoglycaemia. 
Whereas our small sized initial study (12) showed an overrepresentation of * $2 /{ }^{*} 3$ and ${ }^{*} 3 /{ }^{*} 3$ genotypes $(10 \%)$ in 20 patients with $\mathrm{SH}$ as compared to the normal population $(2.1 \%)$ our current, substantially larger data could not replicate these findings in this dimension. However, a combined effect of genotype and dosing might have contributed to higher drug exposure in patients with low CYP2C9 activity genotypes thereby increasing their risk for hypoglycaemia. Consistently with previous studies $(20,21)$ our results confirmed the established risk factors for $\mathrm{SH}$ : low HbA1c, advanced age, long diabetes duration, extensive comorbidity with higher degrees of renal insufficiency and polypharmacy thus highlightening the general representativity and validity of our cohort. Surprisingly, in the Go-DARTS Study there was a lack of effect of the ${ }^{*} 3{ }^{*} 3$ genotype on $\mathrm{HbA} 1 \mathrm{c}$ reduction (17) indicating that the individual response to SUs - and also the risk for $\mathrm{SH}$ - are pathophysiologically complex and multifactorial. Besides the influence of CYP2C9 variants polymorphisms of other genes might also be involved in the individual response to SUs and the risk of $\mathrm{SH}$. Plausible candidate genes could be those involved in control of B-cell function such as KCNJ11 (potassium inwardly-rectifying channel, subfamily $\mathrm{J}$, member 11) or Transcription factor 7-like 2 (TCF7L2). In a subgroup of our present 102 individuals with $\mathrm{SH}$ we could demonstrate that those carrying the $\mathrm{K}$ variant of the E23K polymorphism in KCNJ11 have reduced response to SU therapy, which results in increased $\mathrm{HbA}_{1 \mathrm{c}}$ and consequently in lower risk for $\mathrm{SH}$ (22). Continuing advances in genetic discovery will uncover further loci that are associated withT2DM, including variants that appear to modify responses to SUs. 
Additional medication metabolized also through CYP2C9 might reduce the metabolism of SUs and by increasing their hypoglycaemic effects might ultimately result in $\mathrm{SH}$. $24 \%$ of subjects with $\mathrm{SH}$ versus $49 \%$ of our control group received additional medication, which were also main substrates of CYP2C9. So it is unlikely that CYP2C9-dependent comedication would be responsible for the lower $\mathrm{HbA}_{1 \mathrm{c}}$ as well as $\mathrm{SH}$ events in our cohort. It is also noteworthy, that the creatinine clearance was significantly lower in our control group. Based on this, the control group would actually have been expected to be at higher risk for SH. Thus, CYP2C9-dependent comedication and higher degree of renal impairment do not explain the higher risk for $\mathrm{SH}$ either.

In conclusion, our data suggest that under the conditions of everyday practice, individual susceptibility for $\mathrm{SH}$ associated with the use of glimepiride and glibenclamide is complex with HBA1C being the most important clinical risk factor. However, the observed interaction between dose and CYP2C9 genotype leading to potentially higher exposure in slow metabolizers at equal doses, points to the benefit of individualized, and sometimes pharmacogenetics based dosing.

Acknowledgements - The data of this study were obtained within the framework of Michael Hahn's and Olaf Patzer's dissertations. 


\section{References}

1. Duckworth W, Abraira C, Moritz T et al. Glucose control and vascular complications in veterans with type 2 diabetes. N Engl J Med 2009;360:129139

2. Action to Control Cardiovascular Risk in Diabetes Study Group, Gerstein $\mathrm{HC}$, Miller ME et al. Effects of intensive glucose lowering in type 2 diabetes. N Engl J Med 2008;358:2545-2559

3. ADVANCE Collaborative Group, Patel A, MacMahon S et al. Intensive blood glucose control and vascular outcomes in patients with type 2 diabetes. $\mathrm{N}$ Engl J Med 2008;358:2560-2572

4. Currie CJ, Peters JR, Tynan A et al. Survival as a function of $\mathrm{HbA}(1 \mathrm{c})$ in people with type 2 diabetes: a retrospective cohort study. Lancet $2010 ; 375: 481-489$

5. Amiel SA, Dixon T, Mann R et al. Hypoglycaemia in type 2 diabetes. Diab Med 2008;25:245-254

6. Holstein A, Hammer C, Hahn M et al. Severe sulphonylurea-induced hypoglycaemia - a problem of uncritical prescription and deficiencies of diabetes care in geriatric patients. Expert Opin Drug Saf 2010;9:675-681

7. Kirchheiner J, Bauer S, Meineke I et al. Impact of CYP2C9 and CYP2C19 polymorphisms on tolbutamide kinetics and on the insulin and glucose response in healthy volunteers. Pharmacogenetics 2002;12:101-109

8. Kirchheiner J, Brockmöller J, Meineke let al. Impact of CYP2C9 amino acid polymorphisms on glyburide kinetics and on the insulin and glucose response in healthy volunteers. Clin Pharmacol Ther 2002;71:286-296 
9. Niemi M, Cascorbi I, Timm $\mathrm{R}$ et al. Glyburide and glimepiride pharmacokinetics in subjects with different CYP2C9 genotypes. Clin Pharmacol Ther 2002;72:326-332

10. Becker ML, Visser LE, Trienekens PH et al. Cytochrome P450 2C9 *2 and *3 polymorphisms and the dose and effect of sulfonylurea in type II diabetes mellitus. Clin Pharmacol Ther 2008;83:288-292

11. Ragia G, Petridis I, Tavridou A et al. Presence of CYP2C9*3 allele increases risk for hypoglycaemia in Type 2 diabetic patients treated with sulfonylureas. Pharmacogenomics 2009;10:1781-1787

12. Holstein A, Plaschke A, Ptak M, Egberts EH, El-Din J, Brockmöller J, Kirchheiner J. Association between CYP2C9 slow metabolizer genotypes and severe hypoglycaemia on medication with sulphonylurea hypoglycaemic agents. Br J Clin Pharmacol 60;2005:103-106

13. Holstein A, Plaschke A, Vogel M-Y et al. Prehospital management of diabetic emergencies - a population-based intervention study. Acta Anaesthesiol Scand 2003;47:610-615

14.Cockroft DW, Gault MH. Prediction of creatinine clearance from serum creatinine. Nephron 1976;16:31-41

15.Wang, R, Chen K, Wen SY et al. Pharmacokinetics of glimepiride and cytochrome P450 2C9 genetic polymorphisms. Clin Pharmacol Ther 2005;78:90-92

16. Suzuki, K, Yanagawa, T, Shibasaki, T et al. Effect of CYP2C9 genetic polymorphisms on the efficacy and pharmacokinetics of glimepiride in subjects with type 2 diabetes. Diabetes Res Clin Pract 2006;72:148-154 
17. Zhou K, Donnelly N, Burch L et al. Loss of function CYP2C9 variants improve therapeutic response to sulfonylureas in type 2 diabetes: a Go-DARTS Study. Clin Pharmacol Ther 2010;87:52-56

18. American Diabetes Association (ADA) Workgroup on Hypoglycaemia. Defining and reporting hypoglycaemia in diabetes. Diabetes Care 2005;28:1245-1249

19.Leese GP, Wang J, Broomhall J et al. Frequency of severe hypoglycemia requiring emergency treatment in type 1 and type 2 diabetes. Diabetes Care 2003;26:1176-1180

20. Asplund K, Wiholm B-E, Lithner F. Glibenclamide-associated hypoglycaemia: a report on 57 cases. Diabetologia 1983;24:412-417

21. Greco D, Oisciotta M, Gambina F et al. Severe hypoglycaemia leading to hospital admission in type 2 diabetic patients aged 80 years or older. Exp Clin Endocrinol Diabetes 2010;118:215-219

22. Holstein A, Hahn M, Stumvoll M et al. The E23K variant of KCNJ11 and the risk for severe sulfonylurea-induced hypoglycemia in patients with type 2 diabetes. Horm Metab Res 2009;41:387-390 
Table 1: Basic characteristics of type 2 diabetic patients with sulphonylurea-induced hypoglycaemia versus control group

\begin{tabular}{|c|c|c|c|}
\hline Variable & $\begin{array}{c}\text { Severe } \\
\text { hypoglycaemia } \\
(\mathrm{n}=102)\end{array}$ & $\begin{array}{l}\text { Control } \\
(\mathrm{n}=101)\end{array}$ & $p$ \\
\hline Sex (female/male) & $45 / 57$ & $51 / 50$ & 0.36 \\
\hline Age (years) & $77.4 \pm 9.2$ & $79.3 \pm 9.2$ & 0.13 \\
\hline Body-Mass-Index $\left(\mathrm{kg} / \mathrm{m}^{2}\right)$ & $26.7 \pm 5.5$ & $27.0 \pm 4.4$ & 0.76 \\
\hline Serum creatinine $(\mathrm{mg} / \mathrm{dl})$ & $1.55 \pm 0,87$ & $1.72 \pm 1.03$ & 0.19 \\
\hline Creatinine-Clearance (ml/min) & $45.8 \pm 22.6$ & $38.0 \pm 18.1$ & 0.02 \\
\hline $\mathrm{HbA1c}(\%)$ & $6.5 \pm 1.2$ & $7.2 \pm 1.3$ & 0.0004 \\
\hline Comedication (number of drugs) & $7.0 \pm 2.8$ & $7.4 \pm 2.8$ & 0.28 \\
\hline Duration of diabetes (years) & $11.0 \pm 9.9$ & $11.5 \pm 8.3$ & 0.71 \\
\hline $\begin{array}{l}\text { Patients with glimepiride } \\
\text { Mean daily dose }\end{array}$ & $\begin{array}{l}76(74.5 \%) \\
2.8 \pm 1.6 \mathrm{mg}\end{array}$ & $\begin{array}{l}81(80.2 \%) \\
2.3 \pm 1.3 \mathrm{mg}\end{array}$ & $\begin{array}{c}0.33 \\
\left(\mathrm{chi}^{2}\right) \\
0.04 \\
\text { (t-test) }\end{array}$ \\
\hline $\begin{array}{l}\text { Patients with glibenclamide } \\
\text { Mean daily dose }\end{array}$ & $\begin{array}{l}25(24,5 \%) \\
6.1 \pm 3.7 \mathrm{mg}\end{array}$ & $\begin{array}{l}18(17.8 \%) \\
5.0 \pm 3.6 \mathrm{mg}\end{array}$ & $\begin{array}{c}0.2 \\
\left(\mathrm{chi}^{2}\right) \\
0.3 \\
\text { (t-test) }\end{array}$ \\
\hline $\begin{array}{l}\text { Patients with gliquidone } \\
\text { Mean daily dose }\end{array}$ & $\begin{array}{l}1(1.0 \%) \\
30 \mathrm{mg}\end{array}$ & $\begin{array}{l}2(2 \%) \\
60 \mathrm{mg}\end{array}$ & 0.62 \\
\hline $\begin{array}{l}\text { Additional treatment with metformin } \\
\text { Mean daily dose }\end{array}$ & $\begin{array}{c}37(36 \%) \\
1731 \pm 602 \mathrm{mg}\end{array}$ & $\begin{array}{c}43(43 \%) \\
1715 \pm 494 \mathrm{mg}\end{array}$ & $\begin{array}{c}0.36 \\
\left(\mathrm{chi}^{2}\right) \\
0.90 \\
\text { (t-test) }\end{array}$ \\
\hline $\begin{array}{l}\text { Additional treatment with insulin } \\
\text { Mean daily dose }\end{array}$ & $\begin{array}{c}29(28 \%) \\
36.4 \pm 22 \text { I.E. }\end{array}$ & $\begin{array}{c}20(20 \%) \\
36.8 \pm 21.5 \text { I.E. }\end{array}$ & $\begin{array}{c}0.15 \\
\left(\mathrm{chi}^{2}\right) \\
0.96 \\
\text { (t-test) }\end{array}$ \\
\hline $\begin{array}{l}\text { Comedication with other CYP2C9- } \\
\text { main substrates }\end{array}$ & $24(24 \%)$ & $33(49 \%)$ & $\begin{array}{l}0.001 \\
\left(\mathrm{chi}^{2}\right)\end{array}$ \\
\hline $\begin{array}{l}\text { Comedication with other drugs } \\
\text { being at least one CYP2C9-substrate }\end{array}$ & $39(39 \%)$ & $32(47 \%)$ & $\begin{array}{l}0.30 \\
\left(\mathrm{chi}^{2}\right)\end{array}$ \\
\hline
\end{tabular}


Table 2: Risk factors for severe hypoglycaemia in 102 sulphonylurea-treated type 2 diabetic patients with severe hypoglycaemia versus control group $(n=101)$

\begin{tabular}{|l|c|c|}
\hline \multicolumn{1}{|c|}{ Variable } & $\begin{array}{c}\text { Relative Risk } \\
(95 \% \mathrm{Cl})\end{array}$ & $\mathrm{p}$ \\
\hline HbA1c $(\%)$ & $1.56(1.20-2.04)$ & $\mathbf{0 . 0 0 1}$ \\
\hline Dose of sulphonylurea & $1.00(0.96-1.04)$ & 0.95 \\
\hline CYP2C9-genotypes ${ }^{*} /{ }^{*} 2,{ }^{*} 2 /{ }^{*} 3$ and ${ }^{*} 3 /{ }^{*} 3$ & $0.58(0.14-2.50)$ & 0.47 \\
\hline $\begin{array}{l}\text { Comedication with other CYP2C9-main } \\
\text { substrates }\end{array}$ & $0.34(0.17-0.65)$ & $\mathbf{0 . 0 0 1}$ \\
\hline $\begin{array}{l}\text { Comedication with other drugs being at } \\
\text { least one CYP2C9-substrate }\end{array}$ & $0.72(0.39-1.34)$ & 0.30 \\
\hline Comedication with insulin & $1.61(0.84-3.09)$ & 0.15 \\
\hline Comedication with ACE-inhibitor & $1.35(0.77-2.34)$ & 0.29 \\
\hline Comedication with analgetics & $1.21(0.59-2.50)$ & 0.60 \\
\hline Comedication with gyrase-inhibitors & $0.99(0.20-5.03)$ & 0.99 \\
\hline Presence of coronary heart disease & $2.38(1.35-4.18)$ & $\mathbf{0 . 0 0 3}$ \\
\hline $\begin{array}{l}\text { Kind of accommodation } \\
\text { (home versus nursing home) } \\
\text { Presence of heart failure }\end{array}$ & $1.46(0.84-2.55)$ & 0.18 \\
\hline Presence of dementia & $1.97(0.94-4.15)$ & 0.09 \\
\hline
\end{tabular}


Table 3: Distribution of different CYP2C9 allelic variants in 102 sulphonylurea-treated type 2 diabetic patients with severe hypoglycaemia versus control group without $\mathrm{SH}$ and versus previously reported diabetic and healthy control samples

\begin{tabular}{|l|c|c|c|c|}
\hline $\begin{array}{l}\text { CYP2C9 } \\
\text { genotypes }\end{array}$ & Cases with SH & $\begin{array}{c}\text { Diabetic controls } \\
\text { without SH } \\
\mathrm{N}=101\end{array}$ & $\mathrm{p}$-value & $\begin{array}{c}\text { Diabetic controls } \\
\text { without SH } \\
\text { (Holstein et al. Br J Clin } \\
\text { Pharmacol, 2005) } \\
\mathrm{N}=337\end{array}$ \\
\hline CYP2C9 ${ }^{*} 1 /{ }^{*} 1$ & $63(61.8 \%)$ & $66(65.3 \%)$ & & $224(66.5 \%)$ \\
\hline CYP2C9 ${ }^{*} 1 /{ }^{*} 2$ & $24(23.5 \%)$ & $9(8.9 \%)$ & & $62(18.4 \%)$ \\
\hline CYP2C9 ${ }^{*} 2 /{ }^{*} 2$ & $1(1 \%)$ & $0(0)$ & $0.04^{(1)}$ & $5(1.5 \%)$ \\
\hline CYP2C9 ${ }^{*} 1 /{ }^{*} 3$ & $12(11.8 \%)$ & $21(20.8 \%)$ & & $39(11.6 \%)$ \\
\hline $\begin{array}{c}\text { CYP2C9 } \\
{ }^{*} 2 /{ }^{*} 3\end{array}$ & $1(1 \%)$ & $2(2 \%)$ & $0.28^{(2)}$ & $5(1.5 \%)$ \\
\hline $\begin{array}{c}\text { CYP2C9 } \\
{ }^{*} 3 /{ }^{*} 3\end{array}$ & $1(1 \%)$ & $3(3 \%)$ & & $2(0.6 \%)$ \\
\hline
\end{tabular}

* - Cases with SH vs. Diabetic controls without SH

** - Cases with SH vs. previously reported Diabetic controls without SH (Holstein et al. Br J Clin Pharmacol, 2005)

*** - Cases with SH vs. previously reported Healthy controls (Holstein et al. Br J Clin Pharmacol, 2005)

(1) $p$-values were calculated by using chi-square tests to compare the overall distribution of CYP2C9 allelic variants between cases and controls

(2) $\mathrm{p}$-values were calculated by using Fisher's exact tests to compare the frequencies of CYP2C9 * $2 /{ }^{*} 3$ and CYP2C $9{ }^{*} 3 /{ }^{*} 3$ allelic variants between cases and controls 